\title{
INFLUENCE OF SILVER SURFACE STRUCTURE ON LUMINESCENCE CHARACTERISTICS OF EUROPIUM DOPED POLYMER FILMS
}

\section{G.A. Denisenko ${ }^{a}$, G.E. Malashikevich ${ }^{b}$, T.V. Tziganova ${ }^{a}$,} V.G. Galstyan ${ }^{a}$, A.P. Voitovich ${ }^{b}$, P.P. Pershukevich ${ }^{b}$, I.I. Kalosha ${ }^{b}$,

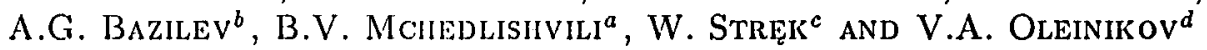

${ }^{a}$ Institute of Crystallography, RAS, Moscow 117333, Russia

${ }^{b}$ Institute of Molecular and Atomic Physics, BAS, Minsk 220002, Belarus

cInstitute for Low Temperatures and Structure Research, Polish Academy of Sciences Okólna 2, 50-950 Wroclaw, Poland

¿IIstitute of Bioorganic Chemistry, RAS, Moscow 117871, Russia

The luminescence characteristics of $\mathrm{Eu}^{3+}$ ions in $\mathrm{Eu}\left(\mathrm{NO}_{3}\right)_{3} \cdot 6 \mathrm{H}_{2} \mathrm{O}$ salt contained in polymer films coating the silver metallic surfaces were studied. The surfaces were specially prepared to consist of silver tip arrays with the height of tips in micron and surface density in $10^{-8} \mathrm{~cm}^{-2}$ ranges. The evaluation of enhancement per one europium ion gave a value $3.5 \times 10^{2}$ for one polymer layer coating of tip array silver surface in comparison with the case of glass substrate coating.

PACS numbers: $78.55 . \mathrm{Hx}$

\section{Introduction}

The optical properties of molecules or ions are drastically changed at or near the surfaces of different metallic structures (rough metal surfaces, metal island films, metal inclusions in media). The well known example is the widely applied phenomenon of surface enhanced Raman scattering (SERS) [1]. The observation of a significant enhancement of luminescence of $\mathrm{Eu}^{3+}$ ions in fluoroborate glasses doped with small silver particles [2] or in thenoltrifluoroacetonate deposited on silver-island films [3] were reported. This phenomenon is very important because of the possibility of essential raising the efficiency of different luminescence devices. The emission properties of rhodamine $6 \mathrm{G}$ in sol-gel containing silver aggregates were also investigated [4] and a twofold enhancement of steady-state luminescence was observed.

Previously $[5,6]$ we reported the studies of luminescence characteristics of $\mathrm{Eu}^{3+}$ ions in $\mathrm{Eu}\left(\mathrm{NO}_{3}\right)_{3} \cdot 6 \mathrm{H}_{2} \mathrm{O}$ salt coating the well-ordered metal structures, i.e. silver tip arrays on silver surface. These arrays were obtained by means of track 


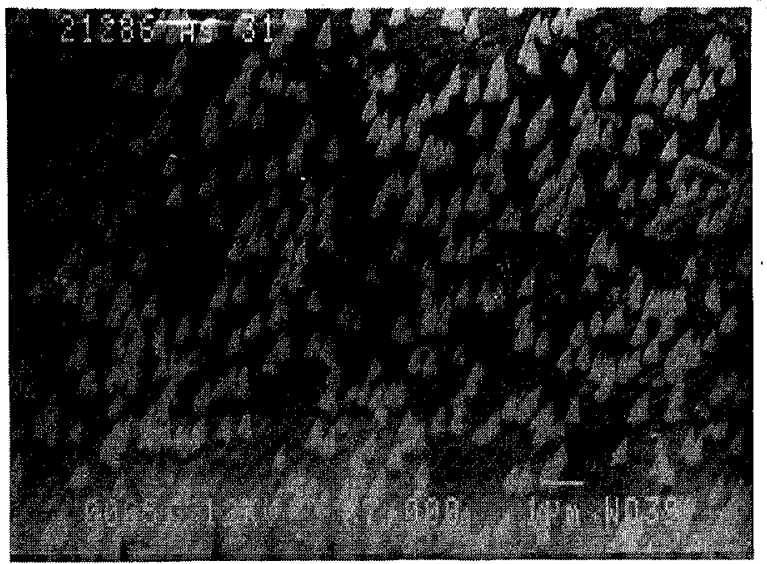

Fig. 1. Micrograph of silver surface with tip arrays. The scale $(1 \mu \mathrm{m})$ is given in the left lower corner.

membranes (nuclear filters). Such metal structures were successfully used in the study of SERS and second harmonic generation $[7,8]$. The metallic structures used in our experiments were obtained by thermal evaporation of silver on track membranes. Track membranes are the polymeric films subjected to heavy ion beam irradiation in accelerators $[7,8]$. A chemical treatment permits to develop pores of the conical form in places of ion passages. Evaporation of silver after that creates a silver surface with tip arrays. Silver surface is reinforced by copper coating. Before experiments the polymeric film is removed.

An example of a silver surface with tip arrays is shown in the micrograph (see Fig. 1) made by using a JSM-840 JEOL electron microscope at the angle $45^{\circ}$. The height of tips is about $500 \mathrm{~nm}$ and the average tip density is about $3 \times 10^{8} \mathrm{~cm}^{-2}$.

The solution of $0.01 \mathrm{~g}$ of $\mathrm{Eu}\left(\mathrm{NO}_{3}\right)_{3} \cdot 6 \mathrm{H}_{2} \mathrm{O}$ in $10 \mathrm{ml}$ of dehydrated acetonate was prepared to coat $2 \mathrm{~cm}^{2}$ of the silver surface with tip arrays. The same procedure was repeated to coat the smooth silver surface for comparative purposes. The emission and excitation spectra were recorded by using a spectrofluorometer SDL-2. The luminescence kinetics was measured by using a spectrofluorometer PRA-3000.

The dependence of luminescence intensity upon tip dimensions (diameter $d$ and height $h$ ) is given in Fig. 2. The excitation was performed at two wavelengths: 315 and $464 \mathrm{~mm}$ corresponding to ${ }^{7} F_{0}-{ }^{5} D_{2}$ hypersensitive transition. The spectra were recorded at room temperature. The greatest value for luminescence enhancement for tip array surfaces in comparison with the case of the smooth silver surface ( $d=h=0$ ) was equal to about 11 times and was obtained for the excitation at $464 \mathrm{~mm}, d=0.2$ and $h=0.3 \mu \mathrm{m}$ and tip density $7 \times 10^{7} \mathrm{~cm}^{-2}$. The calculation of enlancement per one europium ion at the assumption that all amplification is concerned only with ions situated just on tips gives a value $5 \times 10^{2}$. The enhancement in glass [2] was equal to 6, and in the case of silver islands [3] was about 3 times in comparison with the samples without silver. 


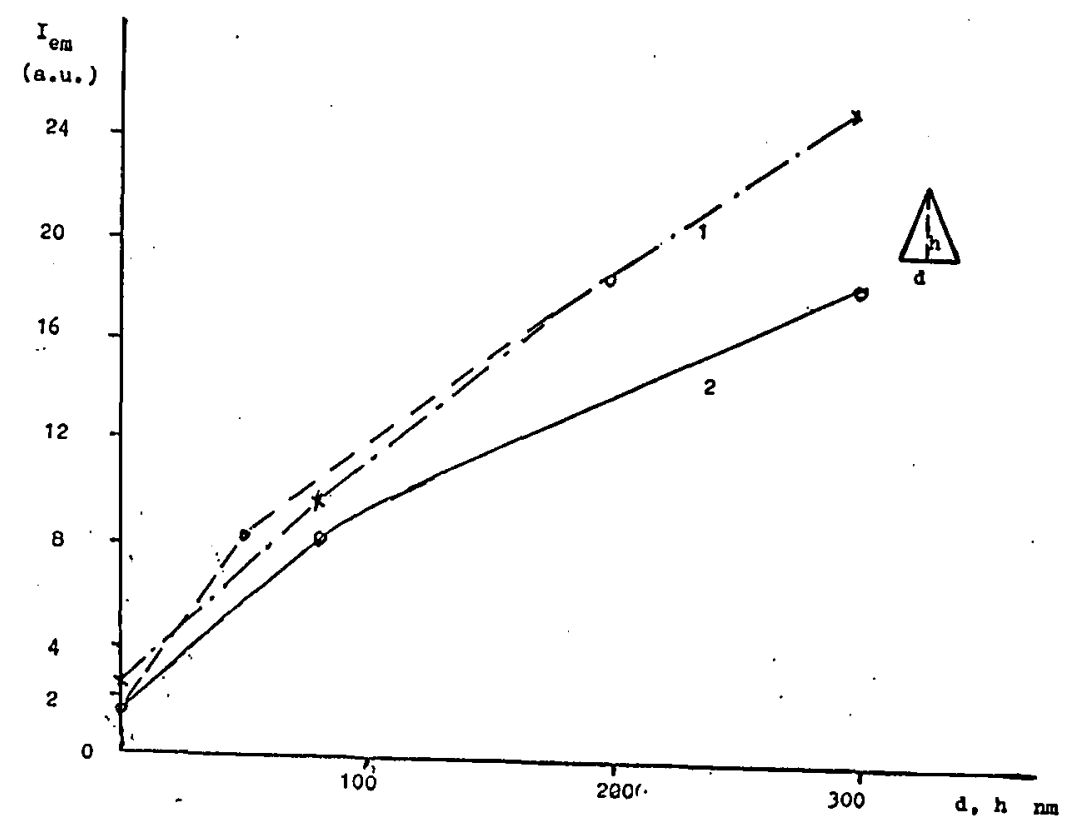

Fig. 2. The dependence of intensities of emission spectra upon the height $(1,2)$ and diameter (3) of tips for the case of $\mathrm{Eu}\left(\mathrm{NO}_{3}\right)_{3} \cdot 6 \mathrm{H}_{2} \mathrm{O}$ salt coating. Excitation at $465 \mathrm{~nm}$ (1) and $315 \mathrm{~nm}(2,3)$.

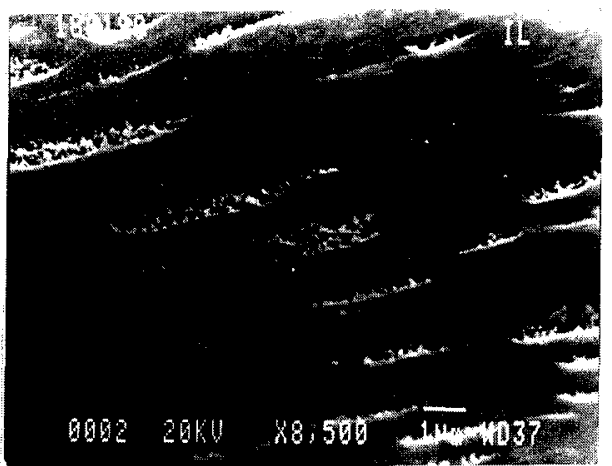

Fig. 3. Micrograph of a silver surface with tip arrays coated by $\operatorname{Eu}\left(\mathrm{NO}_{3}\right)_{3} \cdot 6 \mathrm{H}_{2} \mathrm{O}$ salt layer.

Taking into account wetting, different surface stretching on smooth metal surface and on the surface with tips as well as unsteady drying of the solution it is hard to obtain layers perlectly regular in thickness. The micrograph (see Fig. 3) of the coated surface proved it. The same seems to be true for experiments with silver island films [3]. 
In this work influence of silver surface structure on luminescence characteristics of $\mathrm{Eu}\left(\mathrm{NO}_{3}\right)_{3} \cdot 6 \mathrm{H}_{2} \mathrm{O}$ salt was studied using more stable specimen of better controlled thickness that is important for the enhancement evaluation, viz., polymer films containing europium salt.

\section{Experimental}

Polymer films on the base of polyvinylbutyral containing $\mathrm{Eu}\left(\mathrm{NO}_{3}\right)_{3} \cdot 6 \mathrm{II}_{2} \mathrm{O}$ salt were poured upon silver surfaces with tip arrays (height of tips $-0.7 \mu \mathrm{m}$, the diameter of the cone base $-0.3 \mu \mathrm{m}$, surface density $-4 \times 10^{8} \mathrm{~cm}^{-2}$ ) with following substrate rotation to obtain uniform coating. As a solvent dimethyl formamide was used in which the polymer base and europium salt were well dissolved. The concentration of polyvinylbutyral in solution was $0.1 \mathrm{~g} / \mathrm{l}$, of europium salt $9.5 \mathrm{~g} / \mathrm{l}$. The specimens were dried in the thermostat at $60^{\circ} \mathrm{C}$ during 24 hours.

The quality of coating was controlled by electron microscopy. As it can be seen from the micrograph (Fig. 4) made at the angle $24^{\circ}$ by using a JXA- 840 JEOL we have here coating of better quality. The thickness of a single layer coating was evaluated as $0.3-0.5 \mu \mathrm{m}$, two layer coating as more than $1 \mu \mathrm{m}$.

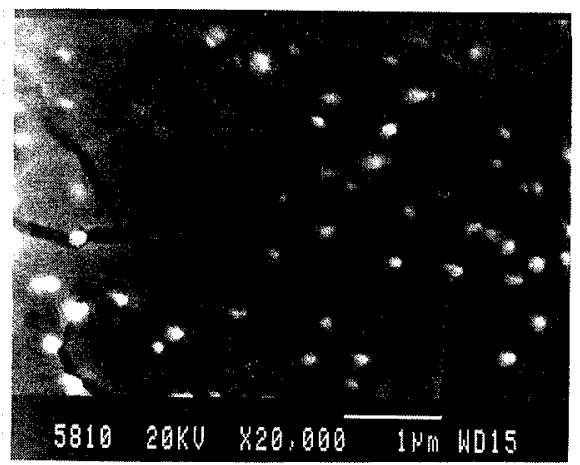

Fig. 4. Micrograph of a silver surface with tip arrays coated by polymer film containing $\mathrm{Eu}\left(\mathrm{NO}_{3}\right)_{3} \cdot 6 \mathrm{H}_{2} \mathrm{O}$ salt.

Luminescence and excitation spectra were recorded by using a spectrofluorometer SDL-2 for one and two layer films on tip surfaces and for a smooth silver surface and silicate glass substrate to compare. The spectra were corrected and presented in terms of the number of quanta per unit interval of wavelengths.

\section{Results and discussion}

The emission spectra (cxcitation at $297 \mathrm{~nm}$ ) are shown in Fig. 5. The integral intensity of luminescence for a single layer coating of the tip array surface was about 10 times higher in comparison with two layer case, about 220 times in comparison with one layer film on the mirror-like silver surface and two orders of magnitude in comparison with the case of one layer film on glass substrate. The evaluation of enhancement per one europium ion at the assumption that all amplification is concerned only with ions situated just near the tips gave a value $3.5 \times 10^{2}$ for one layer coating in comparison with the glass. 


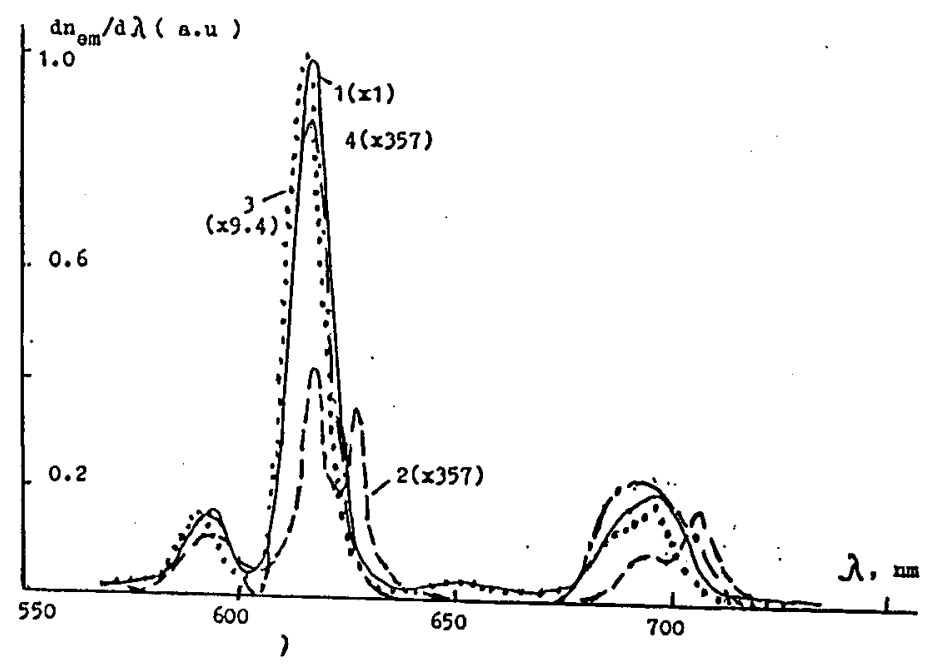

Fig. 5. The emission spectra (excitation at $297 \mathrm{~nm}$ ) for the case of the polymer film containing $\mathrm{Eu}\left(\mathrm{NO}_{3}\right)_{3} \cdot 6 \mathrm{II}_{2} \mathrm{O}$ salt: (1) a single layer coating of silver tip arrays; (2) a single layer coating of a mirror-like silver surface; (3) two layer coating of silver tip arrays; (1) a single layer coating of silicate glass substrate.

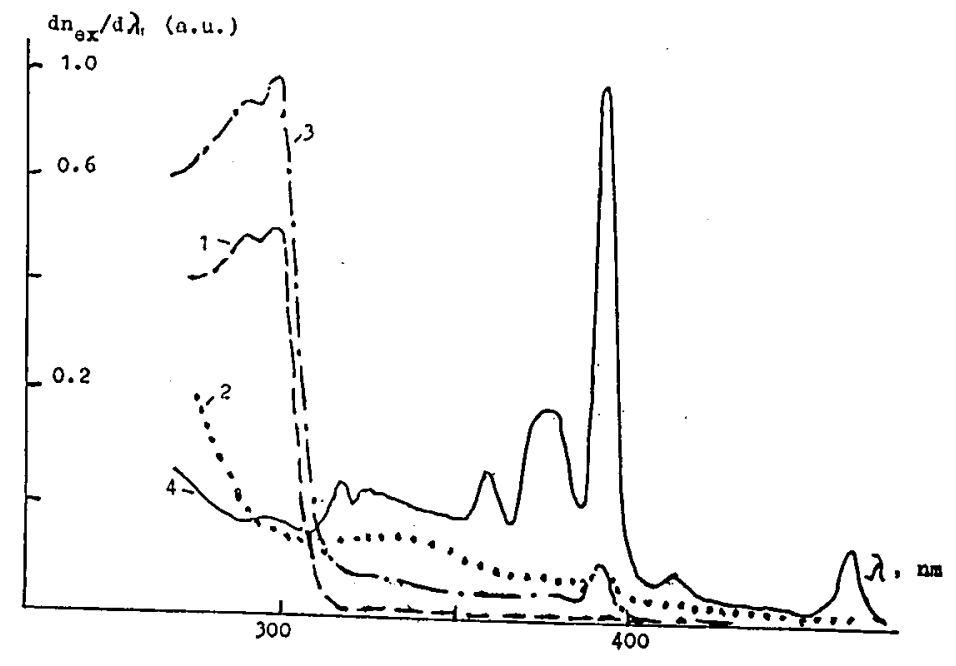

Fig. 6. The excitation spectra (detection at $617 \mathrm{~nm}$ ) for the case of the polymer film containing $\mathrm{Eu}\left(\mathrm{NO}_{3}\right)_{3} \cdot 6 \mathrm{I}_{2} \mathrm{O}$ salt: (1) a single layer coating of silver tip arrays; (2) a single layer coaling of a mirror-like silver surface; (3) two layer coating of silver tip arrays; (4) a single layer coating of silicate glass substrate.

It is known [1] that one of the amplification mechanism in SERS consists in the bonding of studied molecules with surface. Strictly speaking, in this case we study the physical system different from the initial one. This is not important for 
the task of the molecule detection using SERS. But here we try to stay within the electromagnetic model of SERS where the initial system, i.e. $\mathrm{Eu}^{3+}$ ion and its coordination sphere, is not changed. For the sake of control the conservation of the spectrum shape can be used.

From Fig. 5 it can be seen that only in the case of smooth silver surface we have some splitting in the region of $625 \mathrm{~nm}$. At the moment it cannot be easily explained.

The excitation spectra (recorded at $617 \mathrm{~nm}$ ) are shown in Fig. 6. From the analyses of excitation spectra it would be necessary to expect a multiple increase in the broad absorption band at $300 \mathrm{~nm}$ for the tip array surface coating. Under the normalization procedure using the slightly changing band at $395 \mathrm{~nm}$ as a standard the value of amplification at $300 \mathrm{~nm}$ coinciding with the value found from luminescence spectra is obtained. Different presumable explanations of this increase could be proposed. For instance, the formation of charge transfer complexes from ligands to emropium in presence of silver tip arrays, the changes in local environment of europium ions near tip ends and the transfer of energy of collective vibrations of quasilocalized electron system in tips to europium ions.

To clarify the observed phenomenon further experiments are scheduled.

\section{Acknowledgment}

This work was supported by "Russian Foundation for Fundamental Research" (grant 94-02-03879) and partly done in the context of agreement for cooperation between the Institute of Crystallography of RAS, Russia and Institute for Low Temperatures and Structure Research, PAS, Poland. One of us (D.G.A.) is grateful to Prof. F. Anzel and Prof. C.D. Flint for discussions and critics.

\section{References}

[1] Surface Enhanced Raman Scaltering, Eds. R.K. Chang, 'T.E. Furtak, Plenum Press, New York 1982.

[2] O.L. Malta, P.A. Santa-Cruz, G.F. De Sa, F. Auzel, J. Lumin. 33, 261 (1985).

[3] D.A. Weitz, S. Garoff, C.D. IIanson, T.J. Gramila, J.I. Gersten, J. Lumin. 24/25, 83 (1985).

[1] R. Reisfeld, M. Eyal, D. Brusilovsky, Chem. Phys. Lett. 8, 210 (1988).

[5] G.A. Denisenko, V.A. Oleinikov, G.E. Malashkevich, A.P. Voitovich, A.G. Bazilev, B.V. Mchedlish vili, W. Stręk, J. Appl. Spectrosc. 62, 130 (199̀6) (in Russian).

[6] G.A. Denisenko, V.A. Oleinikov, G.E. Malashkevich, A.P. Voitovich, A.G. Bazilev, B.V. Mchedlishvili, W. Stręk, accepted for publication in Mater. Sci. 10, No. 1 (1996).

[7] B.V. Mchedlishvili, V.V. Beriozkin, V.A. Oleinikov, A.I. Vilensky, A.B. Vasiliev, J. Membrane Sci. 79, 285 (1993).

[8] I.A. Kudelina, T.V. Murzina, B.V. Mchedlishvili, V.A. Oleinikov, A.V. Petukhov, K.V. Sokolov, Surface 10, 75 (1991) (in Russian). 